\title{
LA MARCHA DE LOS FLUJOS MIXTOS POR COSTA RICA A LA LUZ DE ALGUNAS TEORÍAS QUE DESCRIBEN LAS MIGRACIONES DEL S XXI
}

\author{
The march of mixed flows through Costa Rica in the light \\ of some theories that describe migrations in the XXI century
}

Cynthia Mora-Izaguirre*

\begin{abstract}
Resumen. Este artículo hace una vinculación teórica (Bauman, Sassen, Salazar y Glick-Schiller) con los Ilamados flujos mixtos de paso por Costa Rica donde se evidencia que son producto de un capitalismo cada vez más fuerte, con una clara presión por eliminar restricciones de mercado y un debilitamiento de los Estados, lo que provoca una selección social de aptitud para incorporarse a nuevos procesos socioeconómicos. Los sectores de la población que no puedan adaptarse tendrán que buscar oportunidades en otros países lejanos, sin importar las distancias y sacrificios que eso conlleve, como es el caso de las migraciones de flujos mixtos de paso por Costa Rica rumbo a Estados Unidos, quienes además de una compleja travesía por las distancias y situaciones que enfrentan, en el 2020 chocan con el cierre de fronteras en la región debido a la pandemia del COVID- 19.
\end{abstract}

Palabras clave: globalización; desigualdad; expulsiones; flujos mixtos.

Abstract. This article makes a theoretical link (Bauman, Sassen, Salazar and Glick-Schiller) between the so-called migration mixed flows phenomenon, passing through Costa Rica. In this, it is evident that these flows are product of an increasingly strong neoliberal approach on human behaviour, with a clear pressure to eliminate market restrictions and a weakening of National States. Naturally, this provokes a process of social selection of aptitude to join new socioeconomic processes. The sectors of the population that cannot adapt will have to search for opportunities in other latitudes, regardless of the distances and sacrifices that this entails. This is the case of migrations of mixed flows passing through Costa Rica to the United States. These migrants face not only a daunting journey, but as 2020, they collide with the closure of borders in the region due to the COVID-19 pandemic.

Keybwords: globalization; inequality; expulsions; mixed flows.

Universidad Nacional, Heredia. Heredia, Costa Rica. E-mail: cmora@una.ac.cr/cynthia mora2000@yahoo.com. Orcid: https://orcid.org/0000-0001-8182-1502. 
En Centro América casi todos los países tienen un perfil más expulsor que receptor, la excepción es Costa Rica, país que históricamente ha recibido más gente de la que ha salido y en los últimos años le ha sumado ser territorio de tránsito de flujos que ingresan por tierra desde Panamá provenientes de América del Sur, sin ser nacionales de esos países. Entonces junto al éxodo de centroamericanos hacia el Norte, hay otros actores que forman parte de estas migraciones, los llamados al inicio como flujos extracontinentales, pero luego llamados flujos mixtos, debido a su gran variedad de nacionalidades y particularidades que hicieron que el término de extracontinentales se hiciera corto ${ }^{1}$.

Este artículo, tiene como objetivo evidenciar esta realidad de la que pocas veces se habla, pues el foco mediático y de investigación académica está generalmente concentrado en la migración del Triángulo Norte hacia Estados Unidos, por las particularidades históricas, políticas y económicas que ha evidenciado. En este caso se tomará en cuenta los datos emanados de Costa Rica, quien atiende a estas poblaciones que vienen desde América del Sur en su búsqueda de un futuro mejor, denominador común con los emigrantes del Triángulo Norte.

De esta manera después de dejar suelo costarricense en su camino hacia el Norte personas provenientes de países muy lejanos como Bangladesh, Congo, Nepal, hasta Cuba y Haití, por citar algunos engrosan los flujos migratorios regionales. Estos flujos de personas provenientes de países externos al área territorial donde se ubican la mayoría de los países americanos forman parte de los retos que tiene la región en la gestión migratoria que debería de velar por el respeto a la dignidad humana de todas las personas que toman como decisión migrar hacia otro país.

Cabe hacer acá la aclaración que estas migraciones de países fuera del área continental ha sido compleja de estudiar por lo retos metodológicos que conlleva, pues algunos llegan de manera irregular por medio de barcos de contenedores que salen de África hacia Brasil u otra manera de llegar es vía área a países como Ecuador, y luego emprenden su marcha hacia el Norte (Mora, 2017; Acuña et al. 2018).

Para entender mejor esta situación, es primordial hacer una descripción teórica sobre cómo se deben de observar estos flujos migratorios, es decir, cuales dinámicas son las que producen el efecto de salida de estas personas de su países de origen, qué dinámicas son a nivel global las que empujan estas migraciones que están influenciadas por aspectos económicos, sociales y políticos, que son los que permean esas decisiones a nivel de unidad familiar, la cual se ve como una estrategia migratoria, pero, aunque parezca que es

Posteriormente se hará una explicación de la evolución del término. 
de la esfera personal, es parte de una dinámica que se puede observar cada vez de manera más clara a la luz de la teoría ligada a la globalización, el capitalismo y la gestión de flujos migratorios (deseados y rechazados).

En primer lugar, se hará una explicación de contexto, tomando algunos elementos expuestos por la socióloga Saskia Sassen (2014). Su enfoque es evidenciar como algunas decisiones y cambios en el modelo económico han provocado procesos de expulsión en diferentes áreas. En este artículo nos enfocaremos al modelo productivo y los trabajadores.

En segundo lugar, se incorporarán algunos elementos de los "regímenes de la movilidad" de los antropólogos sociales Noel B. Salazar y Nina Glick Schiller (2014) quienes hacen una explicación sobre las decisiones en gestión migratoria que permean las políticas que han proliferado. Y, en tercer lugar, se contextualizará con los aportes hechos por el sociólogo y filósofo Zygmunt Bauman (2016) sobre globalización y migración.

Lo anterior permitirá conocer y dimensionar que estas migraciones de paso por Costa Rica van más allá de una decisión familiar o personal, hay elementos globales que provocan que las migraciones que se dan en el siglo XXI tengan particularidades que se pueden vincular de manera clara y directa con los contextos que se han venido desarrollando especialmente desde el fin de la Guerra Fría.

\section{Expulsiones como una manera de funcionar}

Según la socióloga Saskia Sassen (2014), las lógicas que dominan los sistemas en la época actual están muy influenciados por la protección al medio ambiente y las finanzas, incluso por ello es por lo que temas como la innovación y las cuotas de carbono funcionan como una manera de tener permiso de explotar el medio ambiente, de utilizar y explotar los recursos naturales a cambio de algo, es decir, una especie de compensación por sacarles provecho. Se discute también respecto a lo que ella denomina Norte Global versus Sur, Oeste y Este Global, opera en dinámicas sistémicas, muchas veces subterráneas que dividen el mundo en discretas categorías como economías: capitalista, China comunista, África Subsahariana, medio ambiente, finanzas u otras categorías.

Otro de los puntos es que esta nueva lógica ha contribuido a que haya áreas del mundo que se han convertido en estratégicas para subcontratación, manufactura, servicios, proveedores de órganos humanos, de cultivos específicos a bajo costo, todos con pocas regulaciones, "la red de ciudades globales funciona como una geografía de centralidad que cruza a través del viejo Norte-Sur, y divide Este-Oeste y así hace la red de sitios de subcontratación" (Sassen, 2014, p. 9, traducción libre). 
Estos elementos contribuyen a dimensionar el capitalismo de avanzada que promueve la destrucción y la extracción, lo que provoca consecuencias como la exclusión de un número cada vez más creciente de personas que ya no son tomadas en cuenta como trabajadores o consumidores.

En esta línea de argumentación, Sassen resalta los datos sobre cómo los Estados han visto cada vez más afectadas sus finanzas, inclusive cita que según datos del Fondo Monetario Internacional (FMI) utilizados por Isabel Ortiz y Matthew Cummings (Sassen, 2014, p. 24) quienes examinan 181 países con datos de 314 estudios que datan desde antes y después de la crisis del 2008, se evidencia que un cuarto de estos países enfrenta una excesiva contracción, entendiendo esta como un corte en los gastos como parte del PIB. Ortiz y Matthew sostienen que esta situación hace que se consoliden temas fiscales, se agrave el desempleo, se produzcan alimentos a mayor costo y combustibles, así como reducir el acceso a servicios esenciales para muchos hogares, que serán los que deberán pagar el precio de la recuperación.

Como se puede apreciar en estos elementos nombrados, Sassen, explica cuál es la lógica de funcionamiento del sistema mundial: la expulsión, es decir, si un elemento (veáse como persona, empresa, país, etc.) no se adapta a esta lógica de extracción y explotación será expulsada, será rechazada. No todos podrán integrarse a estas lógicas productivas, algunos no encontrarán un lugar y tendrán que buscar suerte en otros espacios o lugares, como es el caso de los migrantes laborales.

\section{La movilidad administrada con la finalidad de limitar o permitir el acceso}

Parte de la dinámica humana y que ningún estudioso del tema niega, es que la movilidad de los seres humanos siempre ha sido parte esencial de su manera de buscar nuevos horizontes que mejoren su calidad de vida, en cualquier ámbito. De hecho, estudios a nivel genético demuestran que la migración está presente en los genes de cualquier persona y aunque algunas personas crean que realmente su origen es totalmente autóctono de esa zona, genéticamente tiene presentes genes de muchos lugares.

Actualmente existe un consenso de varias disciplinas sobre el origen africano y reciente de nuestra especie: los datos paleontológicos y arqueológicos sitúan los yacimientos más antiguos de los humanos al este de África, e incluso la lingüística basada en diversidad de fonemas apunta a algunas lenguas de grupos cazadoresrecolectores del sur del continente como las más antiguas. En este sentido, los datos genéticos apoyan sin ningún tipo de duda al origen de los humanos en África. (Comas, 2014, p. 1)

Aunque la naturaleza humana comprende la necesidad de moverse para buscar buenas condiciones de vida desde los orígenes de la humanidad, el 
nacimiento del Estado-Nación con su conformación de límites de su territorio contribuyó a limitar esas movilidades. En el S. XVII cuando se dio el nacimiento del Estado-Nación, herencia del Tratado de Westfalia (1648) se constituyó los inicios para administrar los territorios de manera más controlada tanto para los individuos como de la comunidad, y con ello poder tener mayor claridad sobre los bienes, propiedades y espacios que se poseían, así como para sentir libertad y seguridad en un espacio determinado. El Estado-Nación se ha ido moldeando por años y parte muy importante de su conformación pasa por su espacio territorial, que está limitado por las fronteras.

Es necesario mencionar que "fronteras" significan: "Líneas que marcan el límite exterior del territorio de un Estado, entendido como el espacio terrestre, marítimo y aéreo sobre el que ejerce su soberanía, lo que permite hablar de fronteras terrestres, marítimas y aéreas en función de la naturaleza física del espacio limitado" (Diccionario PanHispánico). Estas fronteras son las que forman muchas veces un reto de cruzar debido a las restricciones y normas que un Estado tiene para decidir quién entra o no a su territorio.

En la era actual los antropólogos Noel B. Salazar y Nina Glick Schiller plantearon en 2014 una propuesta que evidencia el rol que juegan las fronteras en la manera de administrar la llegada o rechazo de grupos de personas, ellos lo definieron como los "regímenes de la movilidad".

La era actual se distingue por la sensación de un aire de libertad que caracteriza la globalización y, la cada vez más evidente, movilidad de capitales y de facilidades de medios de transporte para moverse y comunicarse, y estas son particularidades de la era actual que no se pueden negar, ni pasar por alto, incluso en esa línea son mencionados por Bauman (2000, 2002, 2007) y Manuel Castells (1996) como parte de los estudiosos que hacen una visión crítica.

Bajo estos aires de libertad que supuestamente promueve la globalización están inmersos los Regímenes de la Movilidad, en los cuales el Estado Nación juega un rol preponderante, él decide quién entra a su territorio y quién es rechazado, "usando las identidades nacionales y las ideologías nacionalista para justificar la exclusión o la inclusión de esos quienes cruzan las fronteras estatales" (Salazar, Glick Schiller, 2014, p. 10, traducción libre).

Estos requerimientos son más evidentes en ciertos países donde cada vez más se limita la entrada a ciertos flujos migratorios, pero se dan facilidades a otros, por ejemplo, a profesionales de las ingenierías o de ciertas áreas de la salud, ellos son objeto de ventajas y facilidades migratorias, al contrario de los flujos laborales de mano de obra no calificada los cuales son muchas veces objeto de muchos requisitos a cumplir para probar su idoneidad, e incluso de 
controles de estancia para apenas cumplen su período obligarles a salir de la manera más eficiente y rápida posible.

Un caso muy evidente en estas dinámicas es Europa quien cada vez fortalece más sus fronteras y requerimientos para ingresar a su territorio, especialmente para los refugiados (Maihold, 2018). Además, no puede olvidarse que muchas de las migraciones de los flujos mixtos son personas provenientes de países que fueron colonias europeas en el pasado, las cuales no gozan de facilidades para ingresar a Europa, entonces toman otros destinos en cuenta.

\section{Bienvenidos los turistas, pero los migrantes no; y menos refugiados}

Zygmunt Bauman destacado sociólogo y filósofo (1925-2017) planteó que las migraciones masivas han sido parte de la modernidad, pues esos flujos de migración masiva eran ya visibles debido a las dinámicas que se habían dado a lo largo de dicha era. Es decir, realmente no tiene nada de nuevo pues este estilo de vida moderno "comporta en sí mismo la producción de «personas superfluas» (localmente «inútiles»-excedentes e inempleables- por culpa del progreso económico, o bien localmente intolerables" (Bauman, 2016, p. 10).

Se puede apreciar ciertas coincidencias en la línea de Sassen, las actuales formas de producción promueven que se den relaciones en la sociedad en la que las personas que no logran encajar en esos modelos de producción, simplemente se vuelven personas que no se ajustan por lo tanto el sistema las rechaza una y otra vez, y especialmente en los países de renta baja donde las prestaciones sociales son muy débiles, la única forma de lograr cierta posibilidad de generar recursos es la movilización ya sea en otras áreas laborales, o a otras áreas geográficas que pueden ser dentro o fuera de ese país.

Sobre esta situación Bauman señaló que "en las zonas «desarrolladas» del planeta en las que tanto migrantes económicos como refugiados buscan acogida, el sector empresarial ve con buenos ojos e inclusos codicia la afluencia de mano de obra barata, cuyas cualificaciones diversas ansían rentabilizar" (Bauman, 2016, p. 11). Estas migraciones que para unos son muy rentables para otros sectores provoca sentimiento de celo y hasta temor.

Como lo señala el mismo autor esta situación se ve acrecentada por la ineficiencia de algunos Estados a los que califica como en derrumbe o ya derrumbados, lo que provoca un sentimiento de "sálvese quien pueda", en el que las personas que salen son generalmente quienes tienen la necesidad urgente de encontrar nuevas oportunidades en otros espacios, no importa dónde e incluso ni siquiera si es en el área que se han preparado académicamente. Lo importante es sobrevivir y poder generar algún bienestar propio o ganancia.

A esa necesidad imperiosa de buscar nuevos horizontes, se une el tema de la brecha salarial, la cual en algunas ocasiones es tal que provoca que, aunque 
el camino hacia el destino sea complicado y peligroso, el tener esa esperanza empuja a buscar ese destino, por ello Bauman cita a Paul Collier (Bauman, 2016, p. 13-14) quien menciona tres elementos en este contexto:

1. Las brechas salariales son brutalmente amplias.

2. La inmigración no disminuirá esas brechas, porque los mecanismos son muy débiles.

3. Por ello la migración está destinada a acelerarse.

En esta línea Collier señaló que es de esperarse que las poblaciones de los países ricos a los pobres se muevan como los "vasos comunicantes" y que alcanzar un equilibrio podría tomar muchos años y eso en condiciones relativamente donde no haya situaciones imprevistas.

$\mathrm{Si}$ a esto que mencionan Bauman y Collier le sumamos en contexto de la pandemia del Covid- 19 en la cual la economía mundial ha sufrido consecuencias sin precedentes es más que claro que estos flujos migratorios se multiplicarán y además abarcarán más cantidad de personas y de países.

Para cerrar este aporte que hace Bauman, él menciona como las personas en Europa y en el mundo llegan a un momento en que ya no les afecta ver el sufrimiento de los migrantes pues son tan bombardeados por este tipo de información que luego llega a generar cierto grado de inmunidad a ese dolor ajeno.

Por último, el miedo a esos desconocidos que "tocan a la puerta" que cuando son turistas son cordialmente recibidos, pero cuando son refugiados o migrantes económicos generan un gran recelo debido al desconocimiento de quiénes son realmente y el temor a que esas personas lleguen a atentar contra la seguridad conocida. Esta puede ser desde económica, espacial y hasta cultural. Se cree que estas personas llegan a provocar cambios en lo que ha venido a ser valorado como el estilo de vida normal y conocido que se disfruta. "El desconocimiento de cómo continuar, de cómo tratar una situación que no hemos creado y que no tenemos bajo control, es la causa fundamental de grandes ansiedades y miedos" (Bauman, 2016, p. 15).

\section{De flujos extracontinentales a flujos mixtos}

A la luz de lo señalado en los párrafos anteriores es que vemos como los métodos de expulsión debido a no poder conseguir un empleo decente mueven a la gente a tomar decisiones de migrar incluso aunque conlleva grandes peligros y largas distancias, además los regímenes imperantes que limitan mucho la movilidad de estas personas "expulsadas" por el sistema económico hacen que las decisiones del destino sean donde haya menos posibilidades de fallar la apuesta, es decir, donde los regímenes les permitan entrar y moverse. En general estas migraciones laborales y de refugiados lo que 
buscan es un futuro con mayores posibilidades de alcanzar mejor calidad de vida, pues ellos son migrantes y no turistas, es decir, los indeseados.

Con estos elementos dimensionados es que se ha podido observar en territorio costarricense numerosas nacionalidades que, aunque quizás al inicio no eran cuantiosas y llamaban la atención por su lejanía y rareza, con el pasar de los años debido a la frecuencia deja de ser una novedad y comienza incluso a gestionarse de una manera específica por parte del Estado, es decir, aplicar, un régimen de movilidad específico para ellos.

"Estas migraciones de tipo irregular se comenzaron a detectar en Costa Rica en el 2008 y es hasta el 2010 cuando se observó un alza en la llegada de inmigrantes africanos y asiáticos" (Mora, 2017, p.190), como señala la autora, poco a poco empiezan a verse más variedad de nacionalidades y ya países como México, Brasil y Colombia, tenían estadísticas de estos flujos en sus territorios, incluso México desde años anteriores al 2008.

Debido a lo poco frecuente y excepcionalidad de este perfil migratorio a estos flujos las autoridades lo empiezan a llamar "extracontinentales". Este término nació el 25 de junio de 2016 cuando las autoridades de la Dirección General de Migración y Extranjería de Costa Rica (DGME) dicen que desde la frontera sur han arribado a territorio costarricense aproximadamente dos mil personas de África y Asia del Sur "que hemos denominado extracontinentales" (Resolución DG-76-06-2016), y que no cumplen con los requisitos legales de ingreso a Costa Rica. Unos meses después (setiembre) a estas personas se les otorga un permiso excepcional de estancia y en ese momento se incluyen también a personas de Haití y reciben el "Permiso de Ingreso y Permanencia Transitoria para Atención Humanitaria" (PIT), exclusivo para estas nacionalidades. Con esa acción se puede identificar un cambio en el "Régimen de la Movilidad" en Costa Rica que permite y facilita el paso de estas migraciones, pero que no promueve su permanencia.

Cabe mencionar que un antecedente de este estatus migratorio fue la llegada en 2015 de miles de cubanos a Costa Rica procedente de Ecuador, con la misma falencia de requisitos migratorios y por la misma ruta por lo que la DGME tuvo que implementar un estatus migratorio excepcional para poder gestionar su atención humanitaria (Acuña et al. 2018).

Se puede observar en esa coyuntura que estos flujos son personas "expulsadas" por la falta de oportunidades en sus lugares de origen, toman la decisión de migrar en búsqueda de un futuro mejor, pero con las particularidades también que no forman parte de un perfil deseable como es ser turistas que llegan a generar ganancias, sino más bien personas que demandan atención por su vulnerabilidad, a esto se hará referencia adelante. 
Ya para el 2019 se empiezan a llamar "flujos mixtos" pues según reconocen las autoridades:

En virtud de los conflictos sociales, políticos, económicos, y culturales suscitados a partir del año dos mil quince, a nivel global, han arribado a la frontera sur de Costa Rica una gran cantidad de personas procedentes que viajan en los flujos migratorios mixtos de nacionalidades regionales y extra-regionales, que no cumplen con los requisitos legales de ingreso a nuestro país, y que, en su mayoría, se presentan indocumentados. (DGME, Resolución N. D. JUR-30-02-2019)

Para poder tener una mejor noción de estos flujos se adjunta una tabla que muestra datos oficiales de estos flujos del 2016, 2017, 2018 y 2019.

Tabla 1 - Cantidad de personas que recibieron PITS por año 2016, 2017, 2018 y 2019, según datos de la DGME, Costa Rica

\begin{tabular}{|c|c|c|c|c|c|c|c|}
\hline \multicolumn{2}{|c|}{2016} & \multicolumn{2}{|c|}{2017} & \multicolumn{2}{|c|}{2018} & \multicolumn{2}{|c|}{2019} \\
\hline \multicolumn{2}{|c|}{18.301} & \multicolumn{2}{|c|}{5.815} & \multicolumn{2}{|c|}{8.963} & \multicolumn{2}{|c|}{$24.102^{1}$} \\
\hline $\begin{array}{l}\text { Mascu- } \\
\text { lino }\end{array}$ & Femenino & $\begin{array}{l}\text { Mascu- } \\
\text { lino }\end{array}$ & Femenino & $\begin{array}{l}\text { Mascu- } \\
\text { lino }\end{array}$ & Femenino & $\begin{array}{l}\text { Mascu- } \\
\text { lino }\end{array}$ & Femenino \\
\hline 13.302 & 4.999 & 5.284 & 531 & 7.754 & 1.209 & 16.137 & 7.965 \\
\hline \multicolumn{2}{|c|}{$\begin{array}{l}\text { Nacionalidad con más } \\
\text { presencia ese año }\end{array}$} & \multicolumn{2}{|c|}{$\begin{array}{l}\text { Nacionalidad con más } \\
\text { presencia ese año }\end{array}$} & \multicolumn{2}{|c|}{$\begin{array}{l}\text { Nacionalidad con más } \\
\text { presencia ese año }\end{array}$} & \multicolumn{2}{|c|}{$\begin{array}{l}\text { Nacionalidad con más } \\
\text { presencia ese año }\end{array}$} \\
\hline \multicolumn{2}{|c|}{$\begin{array}{c}\text { Congo Brazaville } \\
\text { (10.613) }\end{array}$} & \multicolumn{2}{|c|}{ Nepal (2.098) } & \multicolumn{2}{|c|}{ India (2.931) } & \multicolumn{2}{|c|}{ Haití $(8.717)^{2}$} \\
\hline
\end{tabular}

Fuente: Elaboración propia con datos de la DGME, Costa Rica. ${ }^{1}$ En el año 2019 se incluyó a los cubanos en ese conteó de flujos mixtos, fueron 3.044. En los años anteriores la DGME no incluyó a los cubanos en las estadísticas de flujos mixtos. ${ }^{2}$ El paso de los haitíanos se debe a que después de terremoto del 2010, Brasil otorgó visa humantaria a población haitiana, muchos de ellos se ubicaron en trabajos de construcción de estructuras para el Mundial de Fútbol del 2014, y los Juegos Olímpicos 2016 y pero la conclusión de los eventos deportivos junto a la recesión económica de Brasil, empujó a la migración de haitianos hacia el Norte del Continente, en búsqueda del "sueño americano".

En los datos anteriores es muy fluctuante la cantidad de personas que pasan por territorio costarricense, además de las nacionalidades, pero un elemento que se debe resaltar es que estos flujos son los que son contabilizados por la DGME, hay otras cantidades de personas que evaden los controles por ser víctimas de Trata de Personas y Tráfico llícito de Migrantes, y para esos su objetivo es evitar a las autoridades:

El caso más notable involucró un caso de trata laboral transnacional a gran escala, investigado por funcionarios costarricenses y panameños donde presuntos tratantes reclutaron adultos y niños de China e India con falsas promesas de empleos estables y estatus legal. Los tratantes cobraron a estos individuos más de $\$ 20.000$ por transporte $y$, posteriormente, obligaron a por lo menos 14 víctimas a trabajar en restaurantes, bares y mercados para pagar sus deudas. La investigación resultó en el arresto de 31 personas, incluidos 12 funcionarios del gobierno que presuntamente aceptaron sobornos para permitir que las víctimas ingresaran al país sin la documentación adecuada. (Informe de Trata de Personas del Departamento de Estado, 2019) 
Sin embargo, a pesar de los retos a nivel de gestión migratoria, la DGME brinda desde el año 2016 el servicio de atención a estas poblaciones en los Centros de Atención Temporal para Migrantes (CATEM), los cuales son dos y se ubican en cercanías de la frontera sur y norte, este último, por ejemplo

cuenta con 60 tiendas de campaña, recintos de administración, casetilla de Seguridad Pública, enfermería, sala de juegos infantiles y bodega. Posee 34 duchas, 69 cabañas sanitarias, pilas de lavado, fogones, comedor y áreas comunes. También cuenta con iluminación y tendedero en cada una de las tiendas, tubería de agua potable para abastecer a más de 1.000 personas y cuatro tanques con capacidad de almacenar 2500 litros en caso de emergencia. (presidencia.go.cr, 2017)

\section{Coyuntura por Covid-19 para los flujos mixtos}

Desde el 2016 debido a la consolidación de una zona de paso de personas "expulsadas" es que Costa Rica y Panamá Ilegaron a un acuerdo binacional para el traslado ordenado de los flujos mixtos (Plan Estratégico Binacional, 2017), el cual sufrió un cambio abrupto debido a la coyuntura de la pandemia mundial del Covid-19. En este marco de acción cabe mencionar que las acciones de ambos países estaban en facilitar el paso seguro pero continuo de estas migraciones, pues el denominador común en las acciones era promover la continuidad de la movilidad de estas personas, no su permanencia, pues ese ya no solo era el objetivo del régimen de la movilidad en Costa Rica sino también en Panamá.

El virus del Covid-19 llegó a suelo costarricense a inicios de marzo 2020, a partir del día 19 de marzo, al ser las 00:00 horas se comenzó a aplicar la restricción de entrada de personas extranjeras al territorio costarricense por medio del Decreto Ejecutivo № 42238 - MGP- S. Costa Rica cerró sus fronteras, con lo cual el paso de flujos mixtos se vio interrumpido de manera irremediable y los "expulsados" quedaron bajo un régimen de INmovilidad, algo nunca visto en el historia de la humanidad: un cierre masivo de fronteras.

Esto planteó muchos cuestionamientos pues en un contexto de libertades de movimiento de personas y capitales que promueva la globalización quedan atrapadas las personas, incluso con toques de queda en algunos países, lo que también plantea golpes a la economía y los capitales.

En el caso de los flujos mixtos en Costa Rica 260 personas quedaron confinadas en los CATEM atrapados en un contexto de cierre masivo de fronteras en Centroamérica y 2.600 en suelo panameño (Semanario, 2020), pues a excepción de Nicaragua todos los países de Centro América cerraron las fronteras. Particularmente con flujos mixtos Nicaragua tiene prohibición de paso desde hace varios años para ellos a menos que cumplan con todos los requisitos que su normativa define para estos flujos, por lo que su paso por Nicaragua es por medio de vías de tráfico ilícito de migrantes o hacerlo regular 
con cumplimiento de todos los requisitos, lo cual se puede asumir que es la opción más difícil de lograr.

Estas personas que quedaron en los CATEM, al ser su objetivo llegar al Norte, tuvieron unos meses de espera, pero ya el 18 de julio (con 4 meses de estancia) un grupo perdió la paciencia y hubo un amago de violencia, donde se evidenció con la quema de colchones, pues aducían querer retomar ya su ruta hacia EE. UU. (Diario Extra, 18 julio 2020).

Pocos días después de dicho evento un grupo de 97 personas (hombres, mujeres y menores de edad) salió del lugar para retomar su objetivo de seguir su viaje:

La Dirección de Migración asegura que ha conversado con los migrantes para explicarles que las fronteras de Centroamérica se encuentran cerradas por la pandemia y que no podrán cruzar hacia Nicaragua, por lo que les ha instado a permanecer en el CATEM. Sin embargo, Louis afirmó que en el CATEM las condiciones higiénicas son malas y hay hacinamiento, y que lo único que ellos quieren es que los dejen continuar su ruta. Incluso dijo que la caravana tiene el dinero para pagar sus propias pruebas de COVID-19 y presentarlas a las autoridades de Nicaragua y pedir que les dejen avanzar. (Forbes Centroamérica, 2020. Resaltado original)

\section{Apertura de fronteras, pero solo para turistas}

En Costa Rica el turismo es una fuente de empleo muy importante y un sector pujante que en el 2019: "generó al país más de \$3,8 mil millones y unos 156 mil empleos al cierre de 2018, de acuerdo con el Instituto Costarricense de Turismo, y el Instituto Nacional de Estadística y Censos. Por otra parte, el turismo representa un $8 \%$ del Producto Interno Bruto, sumando sus efectos directos e indirectos, según el Banco Central de Costa Rica" (La República, 27/9/2020).

Como se observa el turismo genera mucho encadenamiento productivo y ganancias, por lo cual el cierre de fronteras fue un duro golpe, donde sus ingresos quedaron en cero, y por ello el sector no cesó la presión hacia la apertura para buscar su reactivación en un contexto de compleja y lenta recuperación (buscando dar la bienvenida a los turistas, no a los migrantes ni refugiados).

El Gobierno cedió y a partir del 2 de agosto 2020, por medio del Decreto Ejecutivo 42513-MGP-S algunos vuelos comerciales se les permitió ingresar a territorio costarricense con personas en la categoría de turistas y cumpliendo una serie de requisitos para disminuir los riesgos de contagio y seguros que financiarán la atención médica en caso de requerirlo. Otras categorías migratorias son inadmisibles, entre ellas los flujos mixtos, los indeseables. Acá queda muy claro los postulados de Bauman en los que a los turistas se les dan facilidades para entrar, pero a los "otros" se les niega la entrada. 
Otro de los elementos que llama la atención es que se permitió solo entrada por vía aérea, donde es evidente que las personas deben tener cierto capital para accesar a ese medio de transporte, garantizando de esta manera que entren turistas (figura deseada para la economía). Los países que se les permitió los primeros vuelos comerciales fueron los procedentes de la Unión Europea, Reino Unido y Canadá en un primer momento, semanas después se les permitió también a algunas ciudades de Estados Unidos. Medios de transporte terrestres, fluviales y marítimos se mantenían cerrados hasta al 30 de setiembre de 2020 y con posibilidades de prologar esos cierres.

\section{Reflexiones finales}

Los flujos mixtos constituyen una clara evidencia de las desigualdades y las inequidades que el capitalismo ha sumido al mundo, el recorrer grandes distancias e incluso con sus hijos en brazos o abultados embarazos, solo dejan en evidencia que las expulsiones que provoca el sistema capitalista son cada vez más fuertes, así de fuertes y decididas como la esperanza de estos migrantes por tener un futuro mejor en otro lugar.

Centroamérica enfrenta el reto de vivir grandes desigualdades a nivel estructural, pero eso no la exceptúa de también ser parte y promover regímenes de movilidad que promuevan salir de su territorio (flujos de centroamericanos hacia EE. UU.) e incluso crear estatus migratorios para que estas poblaciones de paso sigan y no permanezcan más de lo estrictamente necesario en este caso en Costa Rica. Estatus con mayores beneficios, así como espacios cómodos para vivir, podrían incentivar quedarse y ese no es el objetivo de ningún país centroamericano, pues a excepción de Panamá y Costa Rica, los otros países no brindan a estos flujos espacios de estancia gubernamentales, solo administrados por ONG'S, ahí queda más claro cuan ignorados e indeseables son.

Reflexiones de Sassen sobre las expulsiones se ven reflejadas en los largos trayectos de estas personas provenientes de países alejados, donde la pobreza, la violencia y la desigualdad expulsa a estos hombres, mujeres y menores de edad que se ven caminar por las calles de Latinoamérica con el objetivo de llegar al Norte.

La pandemia del Covid-19 no solo vino a desnudar las desigualdades que ya se conocían, sino a profundizarlas con la falta de empleo y la recesión económica que provocará mayores expulsiones en un contexto capitalista, que se ensaña con la libre competencia y el consumo desenfrenado, donde los pobres terminarán más pobres, y los ricos más ricos... sino que lo nieguen los dueños de los "Bezos" que se compran en línea.

Las migraciones de los flujos mixtos no son una rareza, no dejan de ser importantes por no ser cientos de miles, incluso con uno que fuese que migre 
por ser expulsado, que no sea bienvenido por no ser turista, pero atractivo para explotarlo, es señal de la gran tarea que tenemos las ciencias sociales en no dejar solas a estas poblaciones, no dejar de lado la tarea de ser su voz: "La humanidad está en crisis y no hay otra manera de salir de esa crisis que mediante la solidaridad entre los seres humanos" (Bauman, 2016, p. 24).

\section{Referencias bibliográficas}

ACUÑA, Guillermo; CHACÓN, Karen; MORA, Cynthia; SOLÍS, Laura. La aplicación cubana: Coyuntura, percepciones y respuestas sobre el impacto de las recientes migraciones caribeñas en territorio costarricense. In: DíAZ, José Andrés (ed.). Paralelo 10 Norte: Líneas imaginarias sobre la migración en Costa Rica. Primera Edición. Heredia, Costa Rica: Escuela de Relaciones Internacionales. Universidad Nacional, 2018.

BAUMAN, Zigmunt. Extraños Ilamando a la puerta. Primera edición. Buenos Aires: Editorial Paidós Estado y Sociedad, 2016.

BAUMAN, Zigmunt. Vida de consumo. Primera edición. México, D.F: Fondo de Cultura Económica, 2007.

BAUMAN, Zigmunt. La Cultura como praxis. Primera edición. España: Editorial Paidós Ibérica, 2002.

BAUMAN, Zigmunt. Modernidad Líquida. Tercera reimpresión 2004. Fondo de Cultura Económica de Argentina, 2000.

CASTELLS, Manuel. The Information Age: Economy, Society and Culture. Vol. I. The Rise of the Network Society. Cambridge, MA - Oxford, UK: Blackwell, 1996.

COMAS, David. La genética de las migraciones humanas siguiendo el rastro de las migraciones a través de nuestro genoma. MÈTODE Science Studies Journal, n. 81, 2014. Disponible en: <https://metode.es/wp-content/uploads/2014/05/81ES3_ genetica_migraciones_humanas.pdf $>$. Acceso en: 22.07.2020.

Dirección General de Migración y Extranjería (DGME). Resolución N. D. JUR -3002-2019.

Dirección General de Migración y Extranjería (DGME). Resolución DG- 76-06-2016.

Dirección General de Migración y Extranjería (DGME). Adendum Resolución N. DG-178-11-2016.

Diccionario PanHispánico. Disponible en: <https://dpej.rae.es>. Acceso en: 20.08.2020.

Embajada de Estados Unidos. Informe de Trata de Personas del Departamento de Estado 2019. 2019. Disponible en: <https://cr.usembassy.gov/es/our-relationshipes/official-reports-es/reporte-2019-de-trata-de-personas-costa-rica/>. Acceso en: 28 de agosto 2020.

Extranjeros prenden fuego a centro de aprehensión. Diario Extra, 2020. Disponible en: <https://www.diarioextra.com/Noticia/detalle/424484/extranjeros-prendenfuego-a-centro-de-aprehensi-n>. Acceso en: 18.07.2020. 
Familias haitianas deambulan a pie por Costa Rica camino a Estados Unidos. Forbes Centroamérica, 26.08.2020. Disponible en: <https://forbescentroamerica. com/2020/08/26/familias-haitianas-deambulan-a-pie-por-costa-rica-camino-aestados-unidos/>. Acceso en: 29.08.2020.

Gobierno de Costa Rica. Decreto Ejecutivo N ${ }^{\circ} 42238$ - MGP- S. Cierre de Fronteras Costarricenses. 2020. Disponible en: <https://www.migracion.go.cr/Paginas/ Cierre-de-Fronteras.aspx> . Acceso en: 28 de agosto 2020.

MAIHOLD, Günther. Migración, control de fronteras y acuerdos migratorios de la Unión Europea con terceros países. Julio 2018. Disponible en: < https://www. researchgate.net/publication/326588046_Migracion_control_de_fronteras_y_ acuerdos_migratorios_de_la_Union_Europea_con_terceros_paises $>$. Acceso en 29.10.2020.

Migración masiva de haitianos y africanos compromete cierre de fronteras en pandemia COVID-19. Semanario Universidad, 31.03.2020. Disponible en: $<$ https://semanariouniversidad.com/pais/migracion-masiva-de-haitianos-yafricanos-compromete-cierre-de-fronteras-en-pandemia-covid-19>. Acceso en: 29.08.2020.

MORA, Cynthia. Migraciones en Costa Rica. Un fenómeno histórico y dinámico desde diversas perspectivas disciplinares. Primera Edición. Costa Rica: FLACSO, 2017.

Plan Estratégico Binacional Costa Rica/Panamá 2017-2019. Marco Operacional para las situaciones de Crisis Migratoria (MOCM). 2017. Disponível en: < https:// www.iom.int/sites/default/files/our_work/DOE/MCOF/MCOF-SP-Costa-Rica-andPanama.pdf>. Acceso en: 29.08.2020.

Presidencia de Costa Rica. Centro de Atención Temporal para Migrantes. El Cruce es ejemplo a seguir en trato humanitario. 2017. Disponible en: < https://www. presidencia.go.cr/comunicados/2017/01/centro-de-atencion-temporal-amigrantes-el-cruce-es-ejemplo-a-seguir-en-trato-humanitario/>. Consulta en: 28.08.2020.

Presidencia de Costa Rica, Dirección General de Migración y Extranjería. Plan Integral para la atención de los flujos migratorio mixtos 2018-2022. 2018. Disponible en: $<$ https://www.migracion.go.cr/Documentos\%20compartidos/Centro\%20de\%20 Estad\%C3\%ADsticas\%20y\%20Documentos/Documentos\%20Varios/Plan\%20 Integral\%20para\%20la\%20Atención\%20de\%20Flujos\%20Migratorios\%20 Mixtos\%202018\%20-\%202022.pdf>.

SALAZAR, Noel; GLICK SCHILLER, Nina. Regimes of Mobility. Imaginaries and Relationalities of Power. First Edition. Routledge, 2014.

SASSEN, Saskia. Expulsions. Brutality and Complexity in the Global Economy. Cambridge, Massachusetts - London, England: The Belknap Press of Harvard University Press, 2014.

Turismo tico brilla, pese a lenta economía mundial. La República, 27.09.2019. Disponible en: <https://www.larepublica.net/noticia/turismo-tico-brilla-pese-auna-lenta-economia-mundial $>$. Acceso en: 15.08.2020. 